\title{
The Streptomyces coelicolor A3(2) bldB region contains at least two genes involved in morphological development
}

\author{
Melanie Harasym, ${ }^{1}$ Li-Hong Zhang, ${ }^{1}$ Keith Chater ${ }^{2}$ and Jacqueline Piret $^{1 *}$ \\ ${ }^{1}$ Department of Biology, Northeastern University, Boston, MA 02115, USA \\ ${ }^{2}$ Department of Genetics, John Innes Institute, Norwich NR4 7UH, UK
}

(Received 28 February 1990; accepted 25 April 1990)

\begin{abstract}
Streptomyces coelicolor A3(2) bldB mutants are blocked in the formation of aerial hyphae. A phage library of wildtype $S$. coelicolor DNA was used to isolate recombinant phages which restore wild-type morphological development to several bldB mutants. Of several mutations, one, bld-28, previously mapped at bldB was not complemented by the cloned region, indicating that the bldB locus is composed of at least two distinct genes. Partial localization of bldB-complementing activity showed that a $1.5 \mathrm{~kb}$ fragment is sufficient for complementation of the bld-15 mutation whereas bld-17 requires the same region as well as additional sequences. Under stringent conditions, genomic DNA hybridizing to the cloned sequences was absent from other Streptomyces species, including the closely related Streptomyces lividans 66. DNA sequences causing marked plasmid structural instability in $S$. coelicolor, but not in $S$. lividans, are also located in this region.
\end{abstract}

\section{Introduction}

Colony development in Streptomyces coelicolor A3(2) has been the subject of a number of genetic studies, both traditional and molecular in approach (for a review see Chater, 1984). On solid medium, a vegetative substrate mycelium is formed during the first few days of growth, which then sends up aerial branches above the colony surface, giving it a hairy, white macroscopic appearance. The aerial hyphae develop long chains of haploid spores, held together by a delicate fibrous sheath. These provide the organism with a means of dispersal. Colony differentiation is accompanied by the synthesis of a wide variety of secondary metabolites, not required for growth. In S. coelicolor these include four antibiotics, two of which (actinorhodin and undecylprodigiosin) are easily recognized because they are pigmented. The regulatory mechanisms controlling morphological development in this system present an attractive subject for the study of the temporal and spatial control of gene expression.

One approach to studying morphological development is through the use of morphological mutants. In this paper, we are concerned with bld (bald) mutants which make vegetative mycelium but do not form aerial hyphae. At least seven classes of $S$. coelicolor bld mutants have been defined by phenotypic and genetic analysis:
bldA, bldB, bldC, bldD (Hopwood, 1967; Merrick, 1976), bldF (Puglia et al., 1986; A. M. Puglia, personal communication), bldG and bldH (Champness, 1988). The bld genes map at a number of locations around the $S$. coelicolor circular linkage map. The morphological deficiencies of bldA, bldD, bldG and bld $H$ mutants can be phenotypically corrected by changing the carbon source (Merrick, 1976; Champness, 1988). This suggests that there are alternative pathways for aerial mycelium formation in this species.

bldB mutants form very smooth colonies, leathery in texture, apparently composed only of substrate mycelium. Like most bld mutants, they also have defects in antibiotic production. Eight independent bld mutants have been assigned to bldB, which maps in the 5 o'clock region of the $S$. coelicolor linkage map (Merrick, 1976; Champness, 1988). Here we describe the isolation of a DNA fragment from the wild-type bldB region and the finding that the region is complex in organization.

\section{Methods}

Bacterial strains. The Streptomyces coelicolor A3(2) strains used in this work are listed in Table 1. Streptomyces parvulus ETH 2283, Streptomyces glaucescens ETH 22794, Streptomyces scabies ETH 3171, Streptomyces peucetius ETH 3180, Streptomyces noursei ETH 3027, Bacillus thuringiensis var. israeliensis and Amycolatopsis mediterranei 
Table 1. Streptomyces coelicolor* and $\phi C 31$ strains used in this work

\begin{tabular}{|c|c|c|}
\hline Strain* & Genotype & Reference \\
\hline $\begin{array}{l}\text { Bacteria } \dagger \\
\text { M145 } \\
\text { J1501 } \\
\text { J650 } \\
\text { J668 } \\
\text { J669 } \\
\text { J701 } \\
\text { J703 } \\
\text { J704 } \\
\text { J95 } \\
\text { J118 } \\
\text { P101 }\end{array}$ & $\begin{array}{l}\text { Prototroph } \\
\text { hisAl uraA1 strAl pgl } \\
\text { cysD18 mthB2 agaA7 } \\
\text { cysD18 mthB2 agaA7 bldA39 } \\
\text { cysD18 mthB2 agaA7 bldB43 } \\
\text { mthB2 agaA7 bld-15 } \\
\text { mthB2 agaA7 bld-28 } \\
\text { mthB2 agaA7 bld-17 } \\
\text { cysD18 strAl whiH119 } \\
\text { cysD18 strA1 whiG71 } \\
\text { bld-15 derivative of } \mathrm{J} 1501\end{array}$ & $\left\{\begin{array}{l}\text { Hopwood et al. (1985) } \\
\text { Merrick (1976) }\end{array}\right.$ \\
\hline $\begin{array}{l}\text { Phage } \neq \\
\phi C 31 \text { KC301 } \\
\phi C 31 \text { KC401 } \\
\phi C 31 \text { KC625/626 } \\
\phi C 31 \text { KC628 } \\
\phi C 31 \text { KC628-bld-15 } \\
\phi C 31 \text { KC628-bld-17 }\end{array}$ & $\begin{array}{l}c^{+} \text {att } P^{+}, \text {contains } t s r \\
\Delta c \Delta a t t P, \text { contains } v p h \\
\text { KC401 carrying bld } B^{+} \text {insert } \\
c^{+} \text {derivative of KC626 } \\
\text { KC628 carrying bld-15 } \\
\text { KC628 carrying bld-17 }\end{array}$ & $\left\{\begin{array}{l}\text { Hopwood et al. (1985) } \\
\text { This paper }\end{array}\right.$ \\
\hline
\end{tabular}

* All strains were originally derived from $S$. coelicolor $\mathrm{A} 3(2)$.

$\dagger$ For marker designations see Merrick (1976). Plasmid status is not given.

$\ddagger c$, repressor gene; att $P$, phage attachment site; $\Delta$, deletion; $t s r$, thiostrepton resistance gene; $v p h$, viomycin resistance gene.

$\S$ Two orientations of the cloned insert.

(formerly Nocardia) ATCC 13685 were from the Microbiology Institute, Swiss Federal Institute of Technology, Zürich, Switzerland. Streptomyces lividans 66 (John Innes strain 1326; Lomovskaya et al. 1972), Escherichia coli ED8767 (Murray et al., 1977) and S. coelicolor A3(2) strains were from the John Innes Institute collection.

Phage and plasmid vectors. Derivatives of the temperate bacteriophage $\phi C 31$ (Lomovskaya et al., 1972) were used and are listed in Table 1 . Conditions for phage propagation, enumeration and crosses were as described by Hopwood et al. (1985). $\phi$ C $31 \mathrm{KC} 628$ was obtained from a cross between strains KC626 and KC301 by screening for phages released from a double lysogen which formed turbid plaques and transduced viomycin resistance. The Streptomyces plasmid vectors pIJ702 (Katz et al., 1983), pMEA3 (Hintermann et al., 1985), pIJ364 (Kieser et al., 1982) and pIJ486/7 (Ward et al., 1986) are derivatives of the multicopy plasmid pIJ101 (Kieser et al., 1982).

Bacterial growth. YEME broth (Hopwood et al., 1985) was the culture medium for the preparation of Streptomyces mycelial fragments. Following harvest by centrifugation, pellets were washed in sterile distilled water and stored in $20 \%(\mathrm{v} / \mathrm{v})$ glycerol at $-20^{\circ} \mathrm{C}$. R2YE agar (Hopwood et al., 1985) was used for routine Streptomyces cultures, for the preparation of spores, in the shotgun cloning experiment and for the assessment of the sporulation status of bld mutants. Minimal medium agar (MM; Hopwood et al., 1985) containing mannitol $(0.5 \%$, $\mathrm{w} / \mathrm{v})$ as carbon source was used to assess the sporulation status of whi mutant strains. For light microscopy, coverslip impression preparations were made by the method of Chater (1972).

DNA manipulations. Plasmid and phage DNA were prepared as described by Hopwood et al. (1985). Genomic DNA was purified according to Hintermann et al. (1981). In vitro DNA manipulations were done by standard methods. For the Southern blot and hybridization (Southern, 1975), genomic DNA digests were separated on $0.75 \%(\mathrm{w} / \mathrm{v})$ agarose gels, blotted to Hybond $\mathrm{N}$ membranes (Amersham) and probed with the gel-purified $4 \mathrm{~kb}$ cloned DNA fragment which had been nick-translated with $5^{\prime}-\left[\alpha^{-32} \mathrm{P}\right]$ deoxycytidine $\left(0.3 \mu \mathrm{g} ; 2-3 \times 10^{7}\right.$ c.p.m. $\left.\mu \mathrm{g}^{-1}\right)$. Following prehybridization and hybri- dization in $50 \%(\mathrm{v} / \mathrm{v})$ formamide at $42{ }^{\circ} \mathrm{C}$ the membranes were washed three times for $20 \mathrm{~min}$ at $65^{\circ} \mathrm{C}$ in $0.1 \% \mathrm{SDS}, 2 \times \mathrm{SSC}(1 \times \mathrm{SSC}$ is $0.15 \mathrm{M}-\mathrm{NaCl}, 0.015 \mathrm{M}$-trisodium citrate, $\mathrm{pH} 7.0$ ).

Transductions and transformations. Phage integration was detected as in Piret \& Chater (1985), by selecting for antibiotic resistances carried by the phage vectors: thiostrepton resistance $\left(t s r ; 50 \mu \mathrm{g} \mathrm{ml}^{-1}\right.$ ), viomycin resistance $\left(v p h ; 40 \mu \mathrm{g} \mathrm{ml}^{-1}\right)$. The gene library used to isolate the wild-type bldB region was that of Piret \& Chater (1985), and consisted of PstI genomic DNA fragments from $S$. coelicolor M145 (insert frequency approx. $88 \%$, size range $2 \cdot 5-6 \mathrm{~kb}$ ) inserted into $\phi \mathrm{C} 31$ KC401 (Harris et al., 1983).

For the primary cloning experiment, mycelium of the recipient strain was spread on R2YE agar medium and infected by replica-plating with library phage plaques. (Prior to replica-plating, the $S$. lividans lawn was killed by exposure of the plaque plates to chloroform fumes for $30 \mathrm{~min}$.) Following growth at $30^{\circ} \mathrm{C}$ for $5-6 \mathrm{~d}$, transductants were selected by replica plating to R2YE medium containing viomycin and thiostrepton. For routine transductions, phages and mycelium of the recipient strains were mixed and plated on R2YE, incubated at $30^{\circ} \mathrm{C}$ for $5-6 \mathrm{~d}$, replica plated to R2YE containing the appropriate antibiotic(s) and incubated for $6 \mathrm{~d}$, after which colony morphology of transductants was scored by visual inspection.

Streptomyces protoplasting and transformations were done according to the procedures of Hopwood et al. (1985). E. coli transformations were as described by Tabak et al. (1979).

\section{Results}

\section{Isolation of the bldB region}

The strategy used to clone the wild-type bldB region was similar to that previously described for the isolation of bld A (Piret \& Chater, 1985). The temperate phage vector 
$\phi$ C31 KC401 (Harris et al., 1983) was used in complementation tests with cloned DNA at single copy number level. In this work, complementation refers to the restoration of aerial mycelium and spore chain formation as determined by visual inspection of colonies and microscopic observation of coverslip impressions. Because $\phi \mathrm{C} 31 \mathrm{KC} 401$ contains a deletion eliminating $c$ gene (repressor) function and another deletion eliminating its attP site, the bldB mutant strain ( $6669 ;$ bldB43) used as the indicator for complementation had first to be lysogenized with a $c^{+}$att $P^{+} \phi \mathrm{C} 31$ derivative $(\phi \mathrm{C} 31$ KC301 was used). This lysogen could be transduced to form a viomycin-resistant double lysogen either by homologous recombination between the resident prophage and $\phi \mathrm{C} 31 \mathrm{KC} 401$ or its derivatives or, much less frequently, by recombination between the cloned fragment and its homologue in the chromosome (insertdirected integration).

Mycelium of J669 ( $\phi$ C31 KC301) spread on R2YE plates was infected by mixing with approximately 6000 plaques of the pooled gene library. Only about 500 transductants were obtained after replication on R2YE plus viomycin. This rather low efficiency was attributed to the difficulty of replica-plating the smooth, hard colonies formed by bldB strains and to the fact that the host strain does not allow $\phi \mathrm{C} 31$ multiplication. However, about half of the transductants produced aerial hyphae as well as pigmented antibiotics. This large apparent proportion of potential wild-type bldB clones was attributed to the relative ease of transfer of $\mathrm{Bld}^{+}$ colonies by replica-plating, thereby enriching for the desired clones.

Examination of twelve representative $\mathrm{Bld}^{+}$transductants by phase contrast microscopy revealed that they all produced aerial hyphae and spore chains indistinguishable from those of the wild-type. They also retained the auxotrophic markers (requirements for homoserine and cysteine) of J669. Phages forming clear plaques (since $\phi \mathrm{C} 31 \mathrm{KC} 401$ is $c^{-}$) released from the twelve lysogens were purified and their DNA analysed by restriction enzyme digestion. They shared a Pst $\mathrm{I}$ insert fragment of approximately $4 \mathrm{~kb}$. Phages carrying either orientation of the insert were found and representatives were named $\phi \mathrm{C} 31 \mathrm{KC} 625$ and $\phi \mathrm{C} 31 \mathrm{KC} 626$. Upon retransduction of $\mathrm{J} 669(\phi \mathrm{C} 31 \mathrm{KC} 301)$ with either $\phi \mathrm{C} 31 \mathrm{KC} 625$ or $\phi \mathrm{C} 31$ $\mathrm{KC626}$, nearly all the colonies screened exhibited wildtype morphology. In Fig. 1, electron micrographs illustrate this complementation.

\section{Complementation of other bldB mutants}

In addition to bld-43, Merrick (1976) assigned the bld-15, bld- 17 and bld-28 alleles to the bldB region. $\phi \mathrm{C} 31 \mathrm{KC} 301$ lysogens of representative strains (J701, J704 and J703)
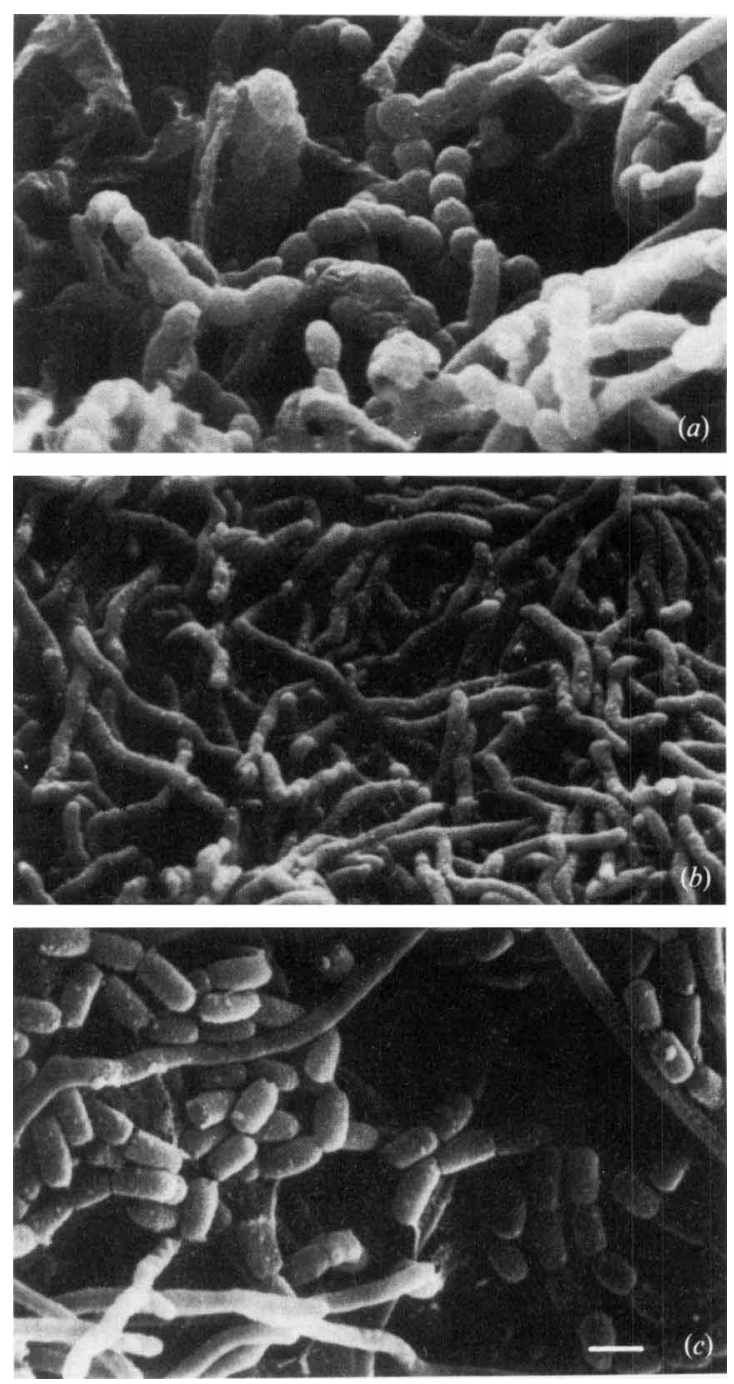

Fig. 1. Restoration of wild-type morphology to a bldB mutant lysogenic for a phage carrying wild-type $S$. coelicolor DNA sequences $(\phi \mathrm{C} 31$ $\mathrm{KC} 626$ ). Scanning electron micrographs (at equal magnification) by $\mathrm{Dr}$ D. Studer. Samples were from 7-d-old colonies grown on R2YE agar containing viomycin and thiostrepton. (a) Parent strain (J650) double lysogen for $\phi \mathrm{C} 31 \mathrm{KC} 301$ and $\phi \mathrm{C} 31 \mathrm{KC} 401$ (the cloning vector); aerial hyphae and spore chains are formed. (b) bldB43 Mutant (J669) lysogenic for $\phi \mathrm{C} 31 \mathrm{KC} 301$ and $\phi \mathrm{C} 31 \mathrm{KC} 401$; only substrate mycelium is formed. (c) bldB43 Mutant (J669) carrying $\phi \mathrm{C} 31 \mathrm{KC} 301$ and $\phi \mathrm{C} 31$ $\mathrm{KC} 626$; aerial hyphae and spore chains are formed. Bar, $1 \mu \mathrm{m}$.

were prepared and transduced with $\phi \mathrm{C} 31 \mathrm{KC} 625$ and $\phi$ C31 KC626. Like J669, J701 and J704 were phenotypically complemented in this way: the vast majority of the transductants were $\mathrm{Bld}^{+}$. Thus bld-43, bld-15 and bld-17 appear to be alleles of the same gene or mutations in closely linked genes present on the $4 \mathrm{~kb}$ fragment.

The rare $\mathrm{Bld}^{-}$colonies found among the complemented transductants probably arose through homogenotization, which sometimes accompanies insert-directed integration of recombinant phages (via the cloned bldB region in this case; Piret \& Chater, 1985). This provided 


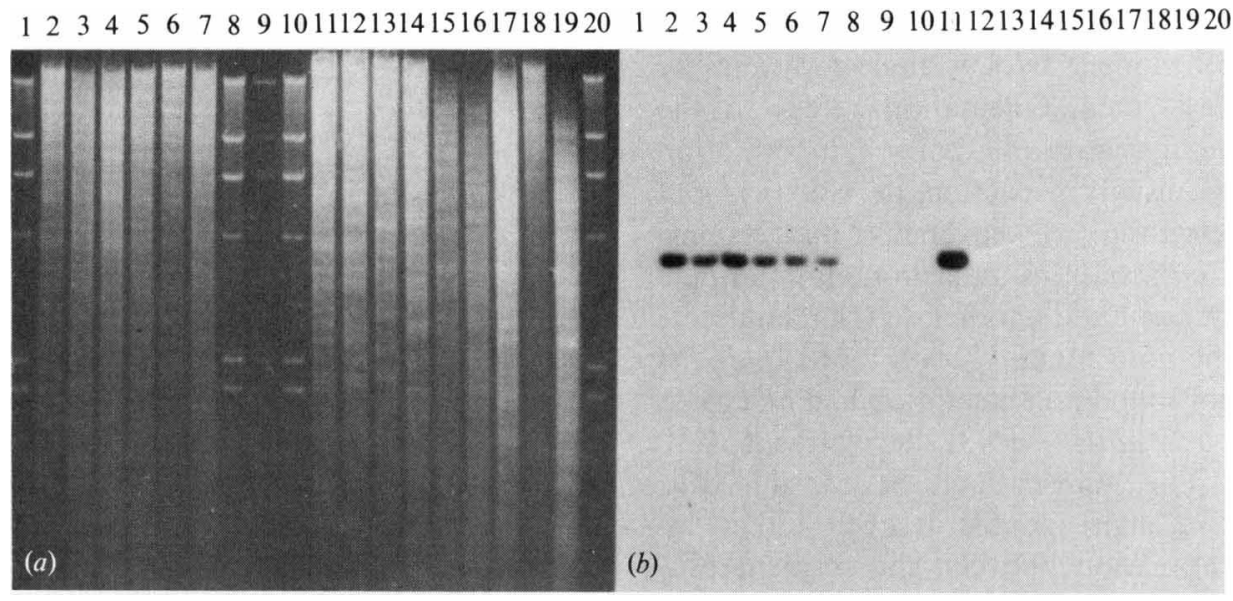

Fig. 2. (a) Gel electrophoresis of $P$ stI digests of total genomic DNA of $S$. coelicolor parent strain and bldB mutants, other Streptomyces species and more distantly related organisms. (b) Hybridization of the $4 \mathrm{~kb}$ bldB fragment. Lanes 1, 8, 9, 10 and 20 ; size standards of $\lambda$ DNA digested with HindIII (23.1, 9.4, 6.6, 4.4, 2.3 and 2.0 kb). Lanes: 2, S. coelicolor J650 (parent); 3, J669 (bld B43); 4, J701 (bld-15); 5, $\mathrm{J} 703$ (bld-28); 6, J704 (bld-17); 7, J668 (bldA39); 11, S. coelicolor M145; 12, S. lividans 66; 13, S. parvulus ETH 2283; 14, S. glaucescens ETH $22794 ; 15, S$. scabies ETH $3171 ; 16, S$. peucetius ETH $3180 ; 17, S$. noursei ETH 3027; 18, B. thuringiensis var. israeliensis; $19, A$. mediterranei ATCC 13685. Hybridization was obtained in lanes 2 to 7 and lane 11.

a method for detecting $b l d B$ mutations carried by phages. Phages released from representative Bld ${ }^{-}$transductants were purified. A $\phi \mathrm{C} 31 \mathrm{KC} 628\left(c^{+} \Delta a t t P\right)$ derivative carrying the bld-15 mutation ( $\phi \mathrm{C} 31 \mathrm{KC} 628-b l d-15)$ was used to move this mutation into a new genetic background, S. coelicolor J1501 (H. Yu \& J. Piret, unpublished). The new strain, $S$. coelicolor P101, exhibited the typical bldB phenotype: smooth, hard colonies independent of the carbon source supplied in the medium. This was good evidence that the cloned DNA fragment carries the wild-type bld $B$ region, rather than a bldB suppressor.

The bld-28 mutant J703 was not complemented by the cloned region. J703 ( $\phi \mathrm{C} 31 \mathrm{KC} 301)$ transduced with $\phi \mathrm{C} 31 \mathrm{KC} 625$ or $\phi \mathrm{C} 31 \mathrm{KC} 626$ produced only very sparse aerial hyphae after prolonged incubation. It was possible that the cloned region includes more than one bld gene and that the sequences corresponding to the bld-28 allele are present but truncated at one end. To test this, $\phi \mathrm{C} 31$ KC628 was used to transduce $\mathrm{J} 703$ by insert-oriented integration. However, no wild-type colonies were found among several hundred transductants screened. A Southern blot of PstI-digested total genomic DNA isolated from the parental strain $\mathrm{J} 650$ and from each bldB strain was probed with the cloned sequences. Hybridization to a $4 \mathrm{~kb}$ fragment was obtained in all cases (Fig. 2, lanes 2 to 7 ). Thus the lack of bld-28 complementation could not be explained by a detectable rearrangement or deletion event in this region in $\mathbf{J} 703$.

Genetic mapping placed $b l d B$ in a region of the $S$. coelicolor linkage map which carries a number of other developmental loci, between whiG and whiH (Merrick, 1976). Thus the ability of $\phi \mathrm{C} 31 \mathrm{KC} 625, \phi \mathrm{C} 31 \mathrm{KC} 626$ or $\phi \mathrm{C} 31 \mathrm{KC} 628$ to complement representative $w h i G$ and whiH mutations (in $\mathrm{J} 118$ and $\mathrm{J} 95$, respectively) was tested. Neither whi strain regained wild-type colony development.

\section{Localization of bld-15 and bld-17 on the cloned fragment}

In experiments to define the cloned sequences required for bldB complementation, the $4 \mathrm{~kb}$ region as well as smaller restriction fragments were introduced into multicopy plasmid vectors and tested in the parent strain $\mathrm{J} 650$ and the mutants J669, J701 and J704. The phenotypes of the J669 (bldB43) transformants were difficult to evaluate since colonies carrying the plasmid vectors with or without cloned insert DNA produced a leaky phenotype for unknown reasons. However, the presence of the vectors had no effect on the morphologies of any of the other strains.

Derivatives of pMEA3 (Hintermann et al., 1985), pIJ364 (Kieser et al., 1982) or pIJ486/487 (Ward et al., 1986) carrying the entire $4 \mathrm{~kb}$ fragment exhibited marked structural instability in J701, J704 or J650. Following growth on selective medium, the colonies formed by the transformants were extensively sectored $\mathrm{Bld}^{+}$and $\mathrm{Bld}^{-}$. Plasmid DNA isolation showed that they carried mixtures of plasmids of sizes smaller than expected. On the other hand, when the same ligations were used to transform $S$. lividans 66 , the expected plasmid constructs were obtained and appeared structurally stable. When plasmid DNA propagated in $S$. lividans was introduced into $S$. coelicolor, plasmid deletions occurred once again. This instability was investigated further, as described in the next section.

$\mathrm{J} 701$ (bld-15) transformed with pNTB01, pNTB02 or 


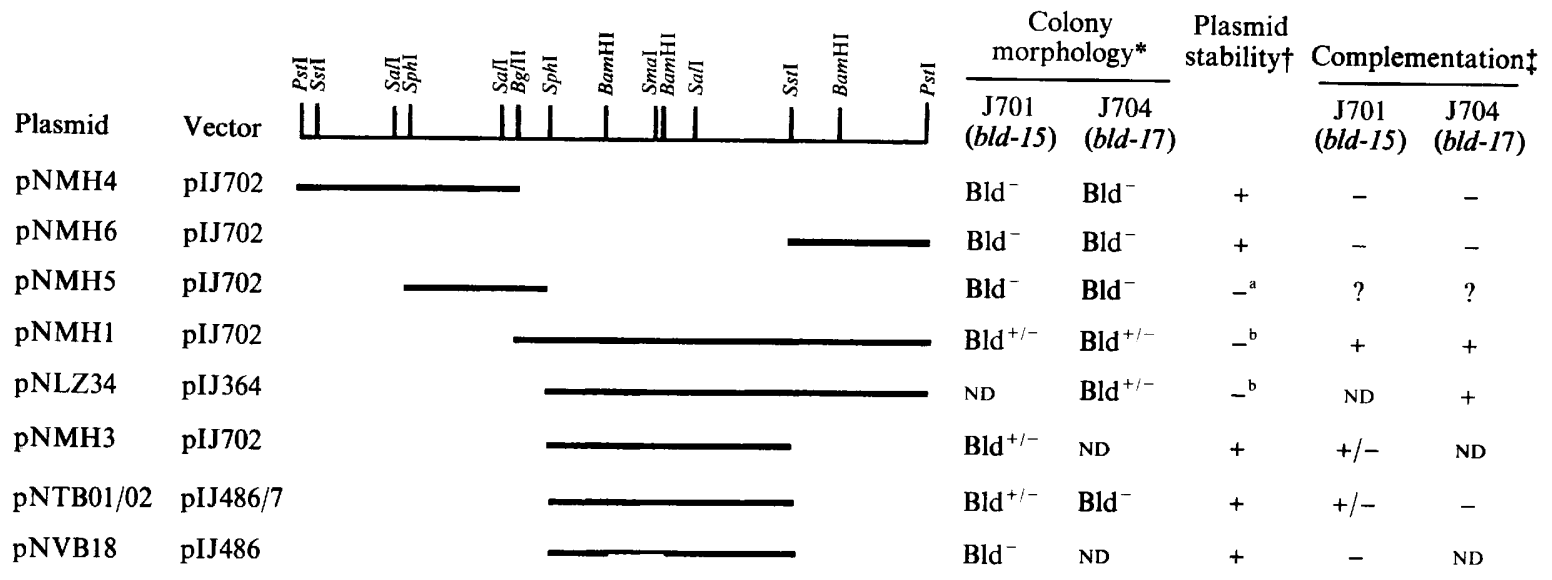

$1 \mathrm{~kb}$

Fig. 3. Restriction endonuclease map of the cloned $4 \mathrm{~kb}$ bldB DNA and phenotypic complementation of bld-15 and bld-17 strains. Sites were mapped using single and double digests of pIJ2154 and pIJ2155 (4 kb bldB PstI fragment in pBR322 in each orientation). The orientation of the map shown is for the fragment in $\phi \mathrm{C} 31 \mathrm{KC} 401$ as drawn by Hopwood et al. (1985), producing $\phi \mathrm{C} 31 \mathrm{KC} 626$. Specific restriction fragments, represented by the thick bars drawn beneath the restriction map, were introduced into the multicopy vectors indicated, producing the plasmids listed. The thin bar in pNVB18 represents a deleted region. *Phenotypic complementation was tested by transformation into $\mathrm{J} 701$ (bld-15) and $\mathrm{J} 704$ (bld-17) and comparison of colony morphology with control strains carrying the plasmid

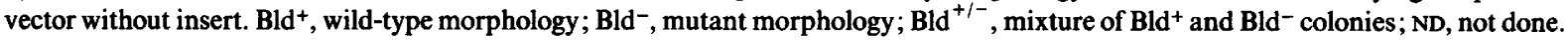
$\dagger$ Plasmid structural stability following growth of the transformants on selective medium: + , all transformants analysed carry a single plasmid species of the expected size; - , some or all transformants analysed carry mixtures of plasmid species smaller than expected. ${ }^{-a}$ All transformants analysed carry plasmid DNA smaller in size than expected. ${ }^{-b}$ Bld $^{+}$transformants carry a single plasmid species of the expected size, $\mathrm{Bld}^{-}$strains harbour a mixture of plasmids smaller in size than expected. $\ddagger$ Complementation pattern: + , fragment complements mutant phenotype; -, fragment does not complement mutant phenotype; ?, complementation uncertain since all transformants examined carry plasmid species smaller in size than expected; $+/-$, transformants are a mixture of $\mathrm{Bld}^{+}$and $\mathrm{Bld}^{-}$ colonies; ND, not done.

pNMH3, which carry a $1.5 \mathrm{~kb} S p h \mathrm{I}-\mathrm{Sst} \mathrm{I}$ fragment originating from the centre region of the original cloned insert (Fig. 3; T. Breidenbach \& V. Bernan, unpublished results), produced a mixture of $\mathrm{Bld}^{+}$and $\mathrm{Bld}^{-}$colonies in a ratio of about $2: 1$. In this case, isolation of plasmid DNA showed that both types of transformants carried plasmids of the expected sizes. Retransformation of J701 with plasmid DNA from each colony type resulted in a similar mixture of $\mathrm{Bld}^{+}$and $\mathrm{Bld}^{-}$colonies in each case. Deletion of a $0.4 \mathrm{~kb}$ BamHI fragment internal to the $1.5 \mathrm{~kb}$ region abolished complementation: all pNVB18 transformants were $\mathrm{Bld}^{-}$(V. Bernan, unpubished results). A representative sporulating J701 pNMH3 strain was cured of its plasmid by growth in the absence of antibiotic (thiostrepton) selection and screening for thiostrepton sensitivity. The seven strains obtained in this way were morphologically $\mathrm{Bld}^{-}$, suggesting that $\mathrm{J} 701$ complementation does not require integration of the cloned sequences but apparently occurs in trans. In no case could pNMH4, pNMH5 or pNMH6 complement the $\mathrm{Bld}^{-}$morphology of $\mathrm{J} 701$.

The complementation pattern for the bld-17 mutant, J704, differed from that for J701 (bld-15). J704-carrying pNTB01 or pNTB02 did not regain wild-type colony morphology. Upon prolonged incubation the transformants developed very sparse aerial hyphae. A larger DNA fragment of about $2.3 \mathrm{~kb}$ which includes the $1.5 \mathrm{~kb}$ bld-15-complementing region was needed to complement J704. Although efforts to complement bld-17 with a stable plasmid construct have so far proved unsuccessful (see below), J704 carrying pNMH1 or pNLZ34 (Fig. 3) produced a small proportion of colonies with wild-type morphology. Examination of the plasmid DNA carried by the transformants revealed, in both cases, that $\mathrm{Bld}^{+}$ strains carried plasmids of the expected sizes whereas $\mathrm{Bld}^{-}$strains contained plasmid populations which were a mixture of sizes smaller than expected.

\section{Localization of DNA sequences affecting plasmid stability}

In addition to restoring wild-type colony morphology to $\mathrm{J} 701$, the presence of the $1.5 \mathrm{~kb} S p h \mathrm{I}-S s t \mathrm{I}$ fragment in pIJ702 leads to plasmid structural instability or strong inhibition of the growth of the host strain. The pattern is shown in Fig. 3. J701 transformants carrying pNMH1 or pNMH3 formed a mixture of $\mathrm{Bld}^{+}$and $\mathrm{Bld}^{-}$colonies. However, plasmids isolated from these strains revealed two different situations. In $\mathrm{Bld}^{+}$strains, pNMH1 
appeared to be intact whereas in bald transformants the plasmid DNA was composed of mixtures of species smaller in size than expected. On the other hand, as noted earlier, both $\mathrm{Bld}^{+}$and $\mathrm{Bld}^{-}$pNMH3 transformants carried a single plasmid species of the expected size. However, the growth of pNMH3 transformants was significantly slower than that of the parent or of $\mathbf{J 7 0 1}$ carrying pIJ702 without insert. Although pNMH4, pNMH5 and pNMH6 did not complement J701, pNMH4 and pNMH6 transformants carried apparently intact plasmid DNA of the expected sizes whereas pNMH5 suffered structural deletions at a high frequency. In addition to pNLZ34, a number of subclones of the bldB region in pIJ364 were also constructed and tested in $\mathbf{J} 701$ and J704. A pattern of structural instability and growth inhibition similar to that seen with the pIJ702 derivatives occurred (data not shown).

Comparison of the inserts carried by the various pIJ702 and pIJ364 derivatives implicates the $0.6 \mathrm{~kb}$ BglII-SphI-BamHI insert fragment shared by pNMH1, pNMH3, pNMH5 and pNLZ34 in the plasmid structural instability and growth inhibition phenomena. The same pattern of plasmid instability and growth inhibition occurred when the various subclones were introduced into other $S$. coelicolor strains such as the parental strain J650 or the prototroph M145. However, in $S$. lividans all of these plamids were structurally stable and the host growth rate was normal.

\section{Absence of the cloned bldB sequences in other species}

A Southern blot of genomic DNA isolated from several Streptomyces species as well as from some more distantly related micro-organisms, was probed with the cloned bld $B$ fragment under stringent conditions (Fig. 2, lanes 11 to 19). Strains of $S$. parvulus, S. glaucescens, $S$. scabies, $S$. peucetius, $S$. noursei, $S$. lividans, $A$. mediterrane $i$ and $B$. thuringiensis var. israeliensis were used. Unexpectedly, none showed homology with the bldB sequences. This was particularly surprising for $S$. lividans, which is closely related to $S$. coelicolor.

\section{Discussion}

The cloned $4 \mathrm{~kb}$ wild-type bldB region restores apparently wild-type aerial hyphae and spore chain formation to the bld-15, bld-17 and bld-43 alleles mapped by Merrick (1976). Complementation by these sequences by integration into a resident prophage at the host at $t$ site indicates that the corresponding wild-type sequences are complete on the cloned DNA fragment and dominant over the mutant alleles. Plasmid subcloning experiments to localize bldB-complementing sequences showed that bld-15 is complemented by a $1.5 \mathrm{~kb}$ fragment while additional adjacent sequences of about $0.8 \mathrm{~kb}$ must also be present ( $2.3 \mathrm{~kb}$ total) for bld-17 complementation. bld15 and bld-17 may lie in separate genes. Alternatively, J704 may carry two bld mutations. The testing of the bld43 strain J669 was prevented by its leaky phenotype when carrying the plasmid vectors with and without insert DNA.

Phenotypic complementation of J701 (bld-15) using stable multicopy plasmid (pIJ486/7) derivatives occurred in about $70 \%$ of the transformants. This suggested that the cloned genes corresponding to this mutation might be truncated and that recombination with the homologous chromosomal region was required for complementation. However, plasmid curing of a Bld $+\mathbf{J} 701$ pNMH3 strain produced only bald colonies, indicating that integration is not required. Some other explanation, involving the nature or function of the bld-15 gene, copy number effects or some physiological variability in the transformants, must be considered to explain the mixture of $\mathrm{Bld}^{+}$ and $\mathrm{Bld}^{-}$morphologies.

In crosses between bld $B$ mutants, Merrick (1976) detected a low frequency of wild-type recombinants in some cases. Upon lysogenization with $\phi \mathrm{C} 31 \mathrm{KC} 625$ or $\phi \mathrm{C} 31 \mathrm{KC} 626$, the bld-28 strain $\mathrm{J} 703$ ( $\phi \mathrm{C} 31 \mathrm{KC} 301$ lysogen) remains bald. One possibility is that bld-28 is a dominant allele of wild-type bldB. However, no Bld ${ }^{+} \mathrm{Vio}^{\mathrm{r}}$ lysogens arising by homogenotization were found among the $\phi \mathrm{C} 31 \mathrm{KC} 628$ transductants. The failure to find $\mathrm{Bld}^{+}$ transductants also rules out the possibility that the sequences corresponding to bld-28 are truncated on the cloned fragment. $\phi \mathrm{C} 31 \mathrm{KC} 628$ integrates by homology with the cloned insert and, at least occasionally, should have generated a wild-type gene during recombinational integration (Piret \& Chater, 1985). Therefore bld-28 is probably not a bldB allele. Champness (1988) isolated three additional $S$. coelicolor bld mutants which she assigned to the bldB region in mating experiments. She reported that two alleles, bld-112 and bld-186, were complemented by $\phi \mathrm{C} 31 \mathrm{KC} 628$, while bld-249 was not. The bld-249 transductants formed sparse aerial mycelium and no spore chains upon prolonged incubation, a phenotype analogous to that of $\mathbf{J} 703$ (bld-28) transductants. Thus bld-28 and bld-249 appear to represent at least one previously unrecognized additional $S$. coelicolor bld gene which maps near, but is not part of, the cloned region. Tentatively, we propose to name this locus bldI. The phenotypes of these mutants, like those of bldB strains, are unaffected by the carbon source provided in the growth medium. Cloning of the bld-28 and bld-249 DNA region(s) will permit the characterization of this new developmental locus and its possible relationship with bldB. 
Derivatives of the multicopy plasmids pIJ702 or pIJ364 carrying inserts from the cloned bldB region were structurally unstable or strongly inhibited the growth of $S$. coelicolor in a number of cases. The presence of the $0.6 \mathrm{~kb}$ fragment containing the BglII-SphI-BamHI cluster of sites (Fig. 3) appears to be responsible for these phenomena. Deleted derivatives of pNMH1, pNMH5 and pNLZ34 occurred at high frequencies. pNMH3 was structurally stable but its presence markedly inhibited the growth of $S$. coelicolor. On the other hand, although they are also derived from pIJ101 (Kieser et al., 1982), pIJ486/487 constructions stably maintained the same bld $B$ sequences. The reason for this stability may be related to the presence of a transcriptional terminator adjacent to the multiple cloning site in pIJ486/487 (Ward et al., 1986). Analysis of the DNA sequence of this region may reveal clues as to the basis for these phenomena.

Examination of colony morphology by coverslip impressions or electron microscopy showed that the cloned bldB region restores apparently wild-type morphological differentiation to complemented mutants. Mendez \& Chater (1987) reported evidence of 'hypersporulation' when the wild-type $S$. coelicolor whiG region was present is two or more copies. whiG is known to encode an RNA polymerase sigma factor required for spore chain formation (Chater et al., 1989). Such copy number effects were not observed in the case of bldB.

Unexpectedly, DNA with significant homology to the bldB region was absent in other Streptomyces species, including the closely related strain $S$. lividans 66. (This may explain the stability of the cloned sequences in multicopy plasmids in this species.) It is possible that although $b l d B$ appears to be unique to $S$. coelicolor at the DNA level, gene product(s) functionally homologous to those which it encodes are produced in other Streptomyces species. There may be processes involved in Streptomyces morphological development which are species-specific. Indeed, different species of Streptomyces are known to produce and to respond to specific regulatory factors controlling morphological and physiological (secondary metabolism) differentiation (Khokhlov, 1988). bldB may play a necessary role in such a specific mechanism in $S$. coelicolor colony development.

Unlike the two previously characterized $S$. coelicolor developmental regions, bldA and whiG, which encode single gene products (Lawlor et al., 1987; Chater et al., 1989), bldB is composed of at least two loci. We have isolated and are analysing one of these. It complements four bldB mutants and corresponds to at least one bld gene. DNA sequencing and analysis of gene expression in the cloned region are in progress with the objective of identifying the nature and function of the gene(s) involved. Efforts are also under way to isolate the second bld $B$ region, now $b l d l$, by complementation of the two remaining ' $b l d B$ ' mutant strains.

We thank Wendy Champness and Gilberto Hintermann for strains and helpful discussions. We are also grateful to William Fowle for his help with photography. This work was supported by a grant from the National Institutes of Health to J.M.P. Early stages of this work were supported by a grant from Cetus Corporation to J.M.P. and by the John Innes Charity.

\section{References}

Champness, W. (1988). New loci required for Streptomyces coelicolor morphological and physiological differentiation. Journal of Bacteriology 170, 1168-1174.

CHATER, K. F. (1972). A morphological and genetic mapping study of white colony mutants of Streptomyces coelicolor. Journal of General Microbiology 72, 9-28.

CHATER, K. F. (1984). Morphological and physiological differentiation in Streptomyces. In Microbial Development, pp. 89-115. Edited by R. Losick \& L. Shapiro. Cold Spring Harbor, NY: Cold Spring Harbor Laboratory.

Chater, K. F., Bruton, C. J., Plaskitt, K. A., Buttner, M. J., Mendez, C. \& Helmann, J. D. (1989). The developmental fate of $S$. coelicolor hyphae depends upon a gene product homologous with the motility sigma factor of B. subtilis. Cell 59, 133-143.

Harris, J. E., Chater, K. F., Bruton, C. J. \& Piret, J. M. (1983). The restriction mapping of $c$ gene deletions in Streptomyces bacteriophage $\phi \mathrm{C} 31$ and their use in cloning vector development. Gene 22, $167-174$.

Hintermann, G., Crameri, R., Kieser, T. \& Hütter, R. (1981). Restriction analysis of the Streptomyces glaucescens genome by agarose gel electrophoresis. Archives of Microbiology 130, 218-222.

Hintermann, G., Zatchej, M. \& Hütter, R. (1985). Cloning and expression of the genetically unstable tyrosinase structural gene from Streptomyces glaucescens. Molecular and General Genetics 200, 422-432.

HopwOOD, D. A. (1967). Genetic analysis and genome structure in Streptomyces coelicolor. Bacteriological Reviews 31, 373-403.

Hopwood, D. A., BibB, M. J., Chater, K. F., Kieser, T., Bruton, C. J., Kieser, H. M., Lydiate, D. J., SMith, C. P., WARD, J. M. \& SCHREMPF, H. (1985). Genetic Manipulation of Streptomyces: a Laboratory Manual. Norwich, UK: The John Innes Foundation.

KatZ, E., Thompson, C. J. \& Hopwood, D. A. (1983). Cloning and expression of the tyrosinase gene from Streptomyces antibioticus in Streptomyces lividans. Journal of General Microbiology 129, 2703-2714.

KHOKHLOV, A. S. (1988). Results and perspectives of actinomycete autoregulators studies. In Biology of Actinomycetes '88, pp. 338-345. Edited by Y. Okami, T. Beppu \& H. Ogawara. Tokyo: Japan Scientific Societies Press.

Kieser, T., Hopwood, D. A., Wright, H. M. \& Thompson, C. J. (1982). pIJ101, a multi-copy, broad host-range Streptomyces plasmid : functional analysis and development of DNA cloning vectors. Molecular and General Genetics 185, 223-238.

Lawlor, E. J., Baylis, H. A. \& Chater, K. F. (1987). Pleiotropic morphological and antibiotic deficiencies result from mutations in a gene encoding a tRNA-like product in Streptomyces coelicolor A3(2). Genes and Development 1, 1305-1310.

Lomovskaya, N. D., Mkrtumian, N. M., Gostimskaya, N. L. \& DANILENKo, V. N. (1972). Characterization of temperate bacteriophage $\phi \mathrm{C} 31$ isolated from Streptomyces coelicolor A3(2). Journal of Virology 9, 258-262.

Mendez, C. \& Chater, K. F. (1987). Cloning of whiG, a gene critical for sporulation of Streptomyces coelicolor A3(2). Journal of Bacteriology 169, 5715-5720.

MERRICK, M. J. (1976). A morphological and genetic mapping study of bald colony mutants of Streptomyces coelicolor. Journal of General Microbiology 96, 299-315. 
Murray, N. E., Brammer, W. J. \& Murray, K. (1977). Lambdoid phages that simplify the recovery of in vitro recombinants. Molecular and General Genetics 150, 53-61.

Piret, J. M. \& Chater, K. F. (1985). Phage-mediated cloning of bldA, a region involved in Streptomyces coelicolor morphological development, and its analysis by genetic complementation. Journal of Bacteriology 163, 965-972.

Puglia, A. M., Alberti, M., Bucca, G., Granozzi, C., Passantino, R. \& MisuraCA, F. (1986). Heat shock proteins and differentiation in Streptomyces coelicolor A3(2). In Fifth International Symposium on the Genetics of Industrial Microorganisms. Abstracts, p. 102. Split, Yugoslavia.
SOUTHERN, E. M. (1975). Detection of specific sequences among DNA fragments separated by gel electrophoresis. Journal of Molecular Biology 98, 503-517.

Tabak, H. F., Hecht, N. B., Menke, H. H. \& Hollenberg, C. P. (1979). The gene for the small ribosomal RNA on yeast mitochondrial DNA: physical map, direction of transcription and absence of an intervening sequence. Current Genetics 1, 33-43.

WARD, J. M., JANSSEN, G. R., KiESER, T., BibB, M. J., BUtTNER, M. J. \& BIBB, M. J. (1986). Construction and characterization of a series of multi-copy promoter-probe plasmid vectors for Streptomyces using the aminoglycoside phosphotransferase gene from Tn 5 as indicator. Molecular and General Genetics 203, 468-478. 